\title{
Study of Feasibility of Single Incision Laparoscopic Surgery with Conventional Instruments
}

\author{
Pankajkumar J Zanwar ${ }^{1}$, Jitendra T Sankpal ${ }^{2}$, Mukund B Tayade ${ }^{3}$, Ajay H Bhandarwar ${ }^{4}$, Shubham D Gupta ${ }^{5}$, Jasmine \\ R Agarwal ${ }^{6}$
}

\begin{abstract}
Aim: To evaluate the feasibility and safety of single incision laparoscopic surgery using conventional laparoscopy instrument set. Materials and methods: Patients admitted in General Surgery Department of Gokuldas Tejpal Hospital, affiliated to Sir Jamshedjee Jeejeebhoy Group of Hospitals, Mumbai, during January 2015 to June 2016 for appendicitis and symptomatic gallstone disease were included in study. Forty cases were enrolled in study and prospective observational study was performed.

Results: Total 40 cases included, 21 cases of appendicitis and 19 cases of symptomatic cholelithiasis. Mean age of appendectomy group was $28.71 \pm 9.69$ years and mean age of cholecystectomy group was $36.71 \pm 10.48$ years. In our study, mean operative time for single-incision laparoscopic (SIL) appendectomy was $42.04 \pm 5.74$ minutes. Postoperative fever was noted in three cases (14.25\%). Mean postoperative pain as per visual analog scale (VAS) score taken after 24 hours on POD 2 was 2.14. Average postoperative stay in hospital was 2.14 days, and portsite infection occurred in one case (4.17\%). Patient satisfaction score obtained on the scale of 1-10 on 1-month follow-up was 7.95, while scar cosmesis score was 7.9. In our study, 19 cases underwent SIL cholecystectomy, of which 7 were male (36.8\%) and 12 were female (41.2\%), and mean age of patients was 36.71 years. Mean operative time in our study was 75.21 min, mean postoperative pain taken on POD 2 as per VAS score was 2.91, mean postoperative hospital stay was 2.1 days, and port-site infections occurred in 2 cases. Postoperative fever was noted in 2 cases, and postoperative patient satisfaction score obtained at 1-month follow-up was 7.73 and scar score of 7.84 on the scale of 0-10. No case required drain placement and conversion.

Conclusion: single-incision laparoscopic surgery (SILS) can be performed using conventional laparoscopic instruments, though it has more operative time, comparable postoperative hospital stay, causes less pain, and has significantly more patient satisfaction regarding postoperative scar and cosmesis.

Clinical significance: Since SILS has more patient acceptance and satisfaction, it can be offered to all patients undergoing laparoscopic surgery, irrespective of unavailability of special instruments and financial constraints, as it can be performed using conventional laparoscopic instruments. Keywords: Laparoscopy instrument set, Single incision laparoscopic surgery, Visual analog scale.

World Journal of Laparoscopic Surgery (2019): 10.5005/jp-journals-10033-1365
\end{abstract}

\section{INTRODUCTION}

Since the introduction of laparoscopy in surgical practice, it has evolved over the years from diagnostic laparoscopy to advanced form and many complicated surgeries are now being performed laparoscopically. Laparoscopic procedures are now considered as gold standard in surgical practice for common surgeries like cholecystectomy, appendectomy, and diagnostic laparoscopy, etc.

The field of minimal invasive surgery has experienced an explosive growth in the last two decades. Though the art of surgery has gone through a complete evolutionary process due to antisepsis, antibiotics, anesthesia, and concept of aseptic surgery spread over centuries, the field of laparoscopic surgery has witnessed major changes only in recent past.

The introduction of minimally invasive surgery has drastically changed the way in which surgeons treat the patients. Initially they relied on their direct senses like vision and touch to diagnose the diseases, monitor the condition of patients, and perform invasive procedures, but now minimal access surgery has changed the entire scenario. Modern surgical methods are aimed at giving cure along with using minimally invasive techniques, with the patient's safety never compromised.

During the era of laparoscopic surgery, common trend has been toward less invasive techniques and a natural extension of the trend is to perform operations without scars. The most prominent
${ }^{1-6}$ Department of General Surgery, Grant Medical College and Sir JJ Group of Hospitals, Mumbai, Maharashtra, India

Corresponding Author: Pankajkumar J Zanwar, Department of General Surgery, Grant Medical College and Sir JJ Group of Hospitals, Mumbai, Maharashtra, India, Phone: +91 9975483248, e-mail: pankaj_ zanwar@yahoo.com

How to cite this article: Zanwar PJ, Sankpal JT, Tayade MB, et al. Study of Feasibility of Single Incision Laparoscopic Surgery with Conventional Instruments. World J Lap Surg 2019;12(1):15-18.

Source of support: Nil

Conflict of interest: None

techniques representing scar less surgery are trans-umbilical single-incision laparoscopic surgery (SILS) and natural orifice transluminal endoscopic surgery (NOTES). ${ }^{1}$

SILS has received increasing attention in recent years. In abdominal surgery, it is an area targeted for intensive investigations. Laparoendoscopic single site surgery (LESS), one-port umbilical surgery (OPUS), and single-port access surgery (SPA) are synonymous with that of SILS. ${ }^{2}$

Several operations have thus been until now performed by SILS technique including cholecystectomy, appendectomy, splenectomy, and sleeve gastrectomy and many more. Many studies

() The Author(s). 2019 Open Access This article is distributed under the terms of the Creative Commons Attribution 4.0 International License (https://creativecommons. org/licenses/by-nc/4.0/), which permits unrestricted use, distribution, and non-commercial reproduction in any medium, provided you give appropriate credit to the original author(s) and the source, provide a link to the Creative Commons license, and indicate if changes were made. The Creative Commons Public Domain Dedication waiver (http://creativecommons.org/publicdomain/zero/1.0/) applies to the data made available in this article, unless otherwise stated. 
are done till date to evaluate the feasibility of SILS and all these study reports have indicated that the SILS technique is safe and feasible in the population undergoing these surgeries and that the operative time with this new technique is reasonable. ${ }^{1}$

This study is performed in a tertiary care institute having conventional laparoscopic instrument set. Till now in our hospital, no study has been conducted to study feasibility of SILS. The purpose of our study was to present our experience with SILS and to evaluate the feasibility and safety of it prospectively.

\section{Materials and Methods}

Setting: Patients admitted in General surgical ward of Gokuldas Tejpal Hospital, affiliated to Grant Government Medical College and Sir JJ Group of hospitals, Mumbai for appendicitis and symptomatic gallstone disease.

Sample size: 40 cases, 21 cases of appendicitis and 19 cases of symptomatic cholelithiasis.

Period of study: January 2015-June 2016.

Study design: Prospective observational study.

\section{Inclusion Criteria}

Patients willing to participate in the study, patients more than 12 years of age (male and female), elective cholecystectomy and appendectomy, and fit for general anesthesia.

\section{Exclusion Criteria}

Patients not willing to participate in the study, patients less than 12 years of age, acute abdominal emergency, pregnancy, unfit for general anesthesia and/or pneumoperitoneum, multiple previous abdominal surgeries, and any mass suspicious of malignancy

\section{Conduction of Study}

Patients were selected for the study after taking careful detailed history, clinical examination, laboratory investigations, and ultrasound examination as described above. The patients eligible for the study were selected, informed, and explained regarding the above study and a proper informed, valid, and written consent taken for participation in the trial.

Patients were kept nil by mouth after $10 \mathrm{pm}$ the previous day of surgery. Patients were shaved and prepared; and informed, valid, and written consent for surgery taken. All patients were informed preoperatively regarding the possibility of conversion to conventional multiport laparoscopy or open surgery depending on intraoperative findings and complications. Proper consent regarding the same was also taken.

All patients received preoperative dose of antibiotic. Patients were operated by experienced laparoscopic surgeons of the hospital with experience of $>50$ SILS procedures done previously. All incisions were infiltrated with local anesthetic at the end of the procedure.

Duration of surgery was measured from the time of incision to the time of closure. Patients were started on liquid diet on the evening of surgery and full diet on the next morning of surgery. All patients were encouraged to mobilize as early as possible. Inj. Diclofenac sodium $50 \mathrm{mg}$ IM was given as analgesic postoperatively on demand by the patient as guided by the visual analog scale (VAS) in which the pain experienced by the patient was graded by the patient on a scale of 1-10 and recorded every 6 hours for the first
24 hours postoperatively. Analgesics were given if VAS score was $>5$. The mean VAS profile on day 1 postoperatively was calculated based on the scores. Time to pass flatus was noted, and patients taking $>24$ hours after surgery to pass flatus were noted as to have ileus.

Patients having fever more than $99^{\circ} \mathrm{F}$ were noted. Dressing was not changed unless there is soakage. Patients were discharged from hospital as soon as they were adequately mobilized and taking full diet with adequate pain relief.

Postoperative hospital stay was measured from the date of surgery to the date of discharge. Patients were asked to follow-up on postoperative day 7 at 1 month and 6 months postoperatively. Suture removal was on postoperative day 7 in all cases. Time to return to normal activity was noted in all patients. Patients were reassessed on all the occasions, and wound infection and portsite herniation were checked. During follow-up, all the patients in the outpatient clinic, at 1 month after surgery, answered two questions: "How much satisfied with the surgery are you?" and "How satisfied are you with the scar of the surgery?" These short questions pretended to know about the degree of satisfaction and the surgical scar cosmetic result in terms of score from 0 to 10 . In this scale, 0 indicates not satisfied at all and 10 indicate excellent.

Responses given by patient were noted in case record sheets. All patients were followed up till 6 months after surgery and were assessed for development of incision related complications like port-site hernia.

\section{Observations and Results}

The following facts and figures are observed from our study (Fig. 1).

Study population included total 40 patients, out of which 21 were cases of appendicitis and 19 were cases of symptomatic cholelithiasis. Study included 14 male and 26 female patients, out of which appendicitis group consists of 7 males and 14 females while cholelithiasis group included 7 males and 12 females. A maximum number of patients in appendicitis group were from age group 21-30 years while cholelithiasis group were 6 cases each in 31-40 and $41-50$ years of age group.

Mean age of patients in appendicitis group was $28.71 \pm 9.69$ years, while in cholelithiasis group, it was $36.71 \pm 10.48$ years.

Mean operative time for single-incision laparoscopic (SIL) appendectomy was $42.04 \pm 5.74$ minutes, while for SIL cholecystectomy, it was $75.21 \pm 7.51$ minutes.

Intraoperative findings were as shown in Table 1.

Intraoperative adhesions of small/large bowel or omentum were found in 12 cases out of 40 (30\%). Hemorrhage was noted in 2 cases out of 40 (20\%). In cholecystectomy group, one patient had bile leak due to perforation of gallbladder intraoperatively (5.26\%). Common bile duct (CBD) injury did not occur in any patient. Conversion to conventional multiport laparoscopy was not needed in any cases (Tables 2 and 3 ).

Postoperative ileus was noted in 7 patients out of which 4 were from appendectomy group and 3 were from cholecystectomy group. Postoperative fever more than $99^{\circ} \mathrm{F}$ was noted in 5 patients, 3 of which belong to appendectomy group and

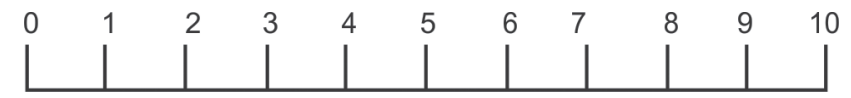

Fig. 1: Scale for scar score and patient satisfaction score 
2 belong to cholecystectomy group. Postoperative pain was measured by using VAS, ranging from 0-10, every 6 hours for first 24 hours and average of the 4 scores was taken. Mean VAS score in first 24 hours was $5.38 \pm 0.58$ in appendectomy group while it was $6 \pm 0.74$ in cholecystectomy group. VAS score was obtained at a point of time, postoperative day 2 in every patient, and mean VAS score on POD 2 was $2.14 \pm$ in appendectomy group while it was $2.21 \pm 0.53$ in cholecystectomy group. Patient received $50 \mathrm{mg}$ of Inj. Diclofenac sodium in first 24 hours as per VAS score. One dose was given every time when VAS score was

Table 1: Intraoperative findings

\begin{tabular}{lll}
\hline Intraoperative finding & Incidence & Percentage \\
\hline Adhesions & $12 / 40$ & 30 \\
Bowel injury & $\mathrm{Nil}$ & 0 \\
Hemorrhage & $2 / 40$ & 5 \\
Bile leak & $1 / 19$ & 5.26 \\
CBD injury & $\mathrm{Nil}$ & 0 \\
Conversion & $\mathrm{Nil}$ & 0 \\
\hline
\end{tabular}

more than 5. Mean analgesic dose requirement was $2.52 \pm 0.60$ doses in appendectomy group while it was $2.94 \pm 0.62$ doses in cholecystectomy group.

Port-site infection occurred in two cases, one from appendectomy and one from cholecystectomy group. In both cases, it was cellulitis around infraumbilical port and was managed conservatively in both cases. Patients were encouraged for mobilization postoperatively as soon as they were comfortable. Patients were discharged from hospital once adequately mobilized and have good pain relief. Mean postoperative hospital stay in appendectomy group was $2.09 \pm 0.30$ days while it was $2.10 \pm 0.31$ days in cholecystectomy group. Mean time to return to normal activity found to be $7.76 \pm 0.83$ days in appendectomy group and $8.84 \pm 0.76$ days in cholecystectomy group.

Scar score given by patients on follow-up at 1 month was noted. Mean scar score in appendectomy group was $7.90 \pm 0.62$ and in cholecystectomy group was $7.84 \pm 0.64$. Patient satisfaction score taken on follow-up at 1 month was in $7.95 \pm 0.58$ appendectomy group and $7.73 \pm 0.45$ in cholecystectomy group. All patients were followed up for minimum of 6 months and no patient found to have port-site hernia.

Table 2: Comparison with other studies of single-incision laparoscopic appendectomy (SILA)

\begin{tabular}{|c|c|c|c|c|c|c|}
\hline \multirow[b]{2}{*}{ Parameters } & \multicolumn{6}{|c|}{ Name of studies } \\
\hline & Our study & Vilallonga et al. $^{3}$ & Oscar et. al. ${ }^{4}$ & Ceciet al. ${ }^{5}$ & Kossi et al. ${ }^{1}$ & Park et al. ${ }^{6}$ \\
\hline Total no. of cases & 21 & 46 & 20 & 12 & 10 & 42 \\
\hline Age (year) & 32.2 & 34.2 & 30 & 23.3 & 37 & 23.9 \\
\hline Operative time (minute) & 42.04 & 52 & 40 & - & 40 & 51.7 \\
\hline Drain placement & 0 & - & $4(20 \%)$ & $3(25 \%)$ & - & - \\
\hline Conversion & 0 & $1(2.17 \%)$ & 0 & 0 & 0 & 0 \\
\hline Postoperative fever & $3(14.2 \%)$ & - & - & $4(33.3 \%)$ & - & - \\
\hline Postoperative ileus & $4(19 \%)$ & - & - & $5(41 \%)$ & - & - \\
\hline Postoperative pain (mean VAS on POD 2) & 2.14 & 2.8 & 2 & - & - & 3.05 \\
\hline Postoperative stay (days) & 2.09 & - & 2 & - & 2 & 2.6 \\
\hline Port-site infection & $1(4.76 \%)$ & - & - & - & $1(10 \%)$ & - \\
\hline Patient satisfaction score & 7.95 & 7.5 & - & - & - & - \\
\hline Scar score & 7.9 & 8.6 & - & - & - & - \\
\hline
\end{tabular}

Table 3: Comparison with other studies of SILC

\begin{tabular}{|c|c|c|c|c|c|}
\hline \multirow[b]{2}{*}{ Parameters } & \multicolumn{5}{|c|}{ Name of study } \\
\hline & Our study & Culp et al. ${ }^{7}$ & Sulu et al. ${ }^{8}$ & Karim et al. ${ }^{9}$ & Van der Linden et al. ${ }^{10}$ \\
\hline Total no. of cases & 19 & 62 & 23 & 45 & 136 \\
\hline Age (year) & 36.71 & 45 & 48.8 & 46 & 45 \\
\hline Operative time (minute) & 75.21 & 65 & 79.1 & 75 & 46 \\
\hline Conversion & 0 & 0 & 5 & $1+2$ & $1+7$ \\
\hline Postoperative fever & $2(10.52 \%)$ & - & - & - & - \\
\hline Postoperative ileus & $39(15.78 \%)$ & - & - & - & - \\
\hline Postoperative pain (mean VAS on POD 2) & 2.21 & - & 2.1 & $\begin{array}{l}0.34 \text { (MEWS } \\
\text { system) }\end{array}$ & - \\
\hline Analgesic doses & 2.91 & - & 3.8 & - & - \\
\hline Postoperative stay (days) & 2.1 & 2.8 & 2.0 & 1 & 1 \\
\hline Port-site infection & 2 & 0 & 4 & 1 & 0 \\
\hline Port-site hernia & 0 & 0 & 0 & 0 & 1 \\
\hline Patient satisfaction score & 7.73 & - & - & - & - \\
\hline Scar score & 7.84 & - & - & - & - \\
\hline
\end{tabular}




\section{Discussion}

Scarless surgery is the Holy Grail of surgery and the main purpose of minimal access surgery was the reduction of scars and thereby pain and suffering of the patients. SILS is a very exciting new modality in the field of minimal access surgery which works for further reducing the scars of standard laparoscopy and toward scarless surgery.

In this prospective observational study, 40 patients were studied. Out of 40 patients, 21 were patients suffering from appendicitis (chronic/recurrent) and 19 were patients of symptomatic cholelithiasis. All of the patients undergone surgery for respective diseases by SILS method.

There were 14 male and 26 female patients in total out of which appendicitis group consisted of 7 males (33.3\%) and 14 females (66.6\%), while cholelithiasis group consisted of 7 males (36.8\%) and 12 females (63.1\%). The ages of patients ranged from 17 years to 53 years with a mean age of 32.2 years. Mean age of appendectomy group was $28.71 \pm 9.69$ years and mean age of cholecystectomy group was $36.71 \pm 10.48$ years.

In our study, mean operative time for SIL appendectomy was $42.04 \pm 5.74$ minutes (from incision to closure), drain placement was not needed in any case, and conversion to conventional multiport laparoscopic appendectomy or open method was not required in any case. Postoperative fever was noted in 3 cases (14.25\%), and postoperative ileus more than 24 hours was noted in 4 cases (19\%). Mean postoperative pain as per VAS score taken after 24 hours on POD 2 was 2.14, average postoperative stay in hospital was 2.14 days, and postoperative port-site infection occurred in one case (4.17\%). Patient satisfaction score obtained on the scale of 1-10 on 1-month follow-up was 7.95, while scar cosmesis score was 7.9 indicating good patient satisfaction with surgery and cosmesis of scar.

Table 2 demonstrates comparison of our study findings with various studies on SILS appendectomy done previously.

In our study, 19 cases underwent SIL cholecystectomy (SILC), of which 7 were male (36.8\%) and 12 were female (41.2\%), and mean age of patients was 36.71 years. Mean operative time in our study was 75.21 minutes, and conversion to conventional multiport laparoscopic cholecystectomy was not needed in any case. Postoperative fever was noted in 2 cases in our study and postoperative ileus $>24$ hours was noted in 3 cases. All cases were managed conservatively. Mean postoperative pain taken on POD 2 as per VAS score was 2.21, average analgesic doses required were 2.91, mean postoperative hospital stay 2.1 days. Port-site infections occurred in 2 cases, which were minor and were managed on oral antibiotics. All patients were followed up for minimum of 6 months, and no case of port-site hernia was noted. In our study, postoperative patient satisfaction score obtained at 1-month follow-up was 7.73 and scar score of 7.84 on the scale of 0-10.

Table 3 demonstrates comparison of our study findings with various studies done on SILS cholecystectomy previously.

All the results in our study were comparable to studies done previously, which were performed using specialized instruments for SILS.
In this study, it was observed that it was possible to perform the procedure with conventional instruments in a timely and safe manner, provided that it be performed by experienced surgeon.

\section{Conclusion}

SILS for appendectomy and cholecystectomy can be performed using conventional laparoscopic instruments, provided surgeon has adequate expertise.

Though SILS has more operative time, it has comparable postoperative hospital stay, causes less pain, has comparable hospital stay, and has significantly more patient satisfaction regarding postoperative scar and cosmesis.

Since SILS has more patient acceptance and satisfaction, it can be offered to all patients undergoing laparoscopic surgery, irrespective of unavailability of special instruments and financial constraints, as it can be performed using conventional laparoscopic instruments.

\section{References}

1. Kossi J, Luostarinen M. Initial experience of the feasibility of single-incision laparoscopic appendectomy in different clinical conditions. Diagn Ther Endosc 2010;2010:240260. DOI: 10.1155/2010/ 240260.

2. Vidal Ó, Valentini M, Ginestà C, et al. Laparoendoscopic single-site surgery appendectomy. Surg Endosc 2010;24(3):686-691. DOI: 10.1007/s00464-009-0661-6.

3. Vilallonga R, Barbaros U, Nada A, et al. Single-port transumbilical laparoscopic appendectomy: a preliminary multicentric comparative study in 87 patients with acute appendicitis. Minim Invasive Surg 2012;2012:492409. DOI: 10.1155/2012/492409.

4. Vidal O, Ginesta C, Valentini M, et al. Suprapubic single-incision laparoscopic appendectomy: a nonvisible-scar surgical option. Surg Endosc 2011;25(4):1019-1023. DOI: 10.1007/s00464-010-1307-4.

5. Ceci F, Orsini S, Tudisco A, et al. Single-incision laparoscopic appendectomy is comparable to conventional laparoscopic and laparotomic appendectomy: our single center single surgeon experience. G Chir 2013;34(7-8):216-219. DOI: 10.11138/ gchir/2013.34.7.216.

6. Park J, Kwak H, Kim SG, et al. Single-port laparoscopic appendectomy: comparison with conventional laparoscopic appendectomy. J Laparoendosc Adv Surg Tech A 2012;22(2):142-145. DOI: 10.1089/ lap.2011.0253.

7. Culp BL, Cedillo VE, Arnold DT. Single-incision laparoscopic cholecystectomy versus traditional four-port cholecystectomy. Proc (Bayl Univ Med Cent) 2012;25(4):319-323. Dol: 10.1080/08998280.2012.11928866.

8. Sulu B, Diken T, Altun $\mathrm{H}$, et al. A comparison of single-port laparoscopic cholecystectomy and an alternative technique without a suspension suture. Ulus Cerrahi Derg 2014;30(4):192-196. DOI: 10.5152/UCD.2014.2717.

9. Karim MA, Ahmed J, Mansour M, et al. Single incision vs. conventional multiport laparoscopic cholecystectomy: a comparison of two approaches. Int J Surg 2012;10(7):368-372. DOI: 10.1016/ j.ijsu.2012.05.017.

10. van der Linden YT, Bosscha K, Prins HA, et al. Single-port laparoscopic cholecystectomy vs standard laparoscopic cholecystectomy: a nonrandomized, age-matched single center trial. World J Gastrointest Surg 2015;7(8):145-151. DOI: 10.4240/wjgs.v7.i8.145. 